\title{
SOLANUM PROTEASE INHIBITORS AND THEIR THERAPEUTIC POTENTIALITIES: A REVIEW
}

\author{
MEENU KRISHNAN VG, MURUGAN K.* \\ Plant Biochemistry and Molecular Biology Laboratory, Department of Botany, University College, Trivandrum, 695034, Kerala, India \\ Email: harimurukan@gmail.com
}

Received: 23 Aug 2016 Revised and Accepted: 05 Oct 2016

\begin{abstract}
Protease inhibitors (PIs) are diverse group of proteins with low molecular weight that are ubiquitous in all life forms. PIs are reducers of the physiological activity of proteases and fascinated the attention of biotechnological researchers. In the evolutionary course, plants have developed diverse adaptive mechanisms of defence against various unfavourable conditions including that of predators and pathogens. Phylogenetic relationships among diverse PI families like serpin, Bowman-Birk, cereal trypsin/ $\alpha$-amylase inhibitor, proteinase inhibitor I, proteinase inhibitor II and cystatin have been evaluated. PIs evolution seems to occur through multiple interacting mechanisms and not commonly seen with other coevolving molecules. Interaction of PIs produced by host organisms and the invasive/dietary protease of pathogens or parasites or predators, leads to a phylogenetic 'arms race' of rapid structural modulation in both interacting proteins. Further, the high rate of retention of gene duplication and inhibitory domain multiplication results the PI as potential model system to trace the basic evolutionary process of functional diversification. The mode of action of PI is either via inactivating the hydrolytic enzymes or depolarization of cell membrane of the pathogens thereby inhibiting its growth and invasion. Generally, PIs possess significant number of disulfide bonds due to cysteine residues that provide them resistance to heat, extremes of $\mathrm{pH}$, and proteolysis. However, PIs have been extracted and purified only from few monocots and dicots plants. Currently, PI genes were used for developing insect-resistant transgenic plants for crop improvements. Classification of PIs over the last several years has been based on structural-functional relationships. This review bridges the gap between the folkloric uses of Solanum PIs, their diversity and biological potentialities.
\end{abstract}

Keywords: Solanum, Protease inhibitors, Biological potentialities, Diversity, Characterization

(C) 2016 The Authors. Published by Innovare Academic Sciences Pvt Ltd. This is an open access article under the CC BY license (http://creativecommons.org/licenses/by/4. 0/) DOI: http://dx.doi.org/10.22159/ijpps.2016v8i12.14836

\section{INTRODUCTION}

Plant PIs are small proteins with a molecular mass range of 4 to 85 $\mathrm{kDa}$. Generally plant PIs are present in significant level in storage tissues, contributing up to $10 \%$ of the total protein content. The first report of PI in nature was revealed by Fermi and Pernossi [1] and are widely distributed in diverse tissues of animals, plants and microbes [2]. Many angiosperm families like Fabaceae, Poaceae, Cucurbitaceae, Solanaceae showed their presence with diverse structural forms. Mostly, PIs have been proven as effective defence molecules against pests and pathogens in in vivo experimentals and also reported their optimal expression in transgenic crops. Most PIs bond with specific active site of the proteases resulting in the formation of stable protease inhibitor complex and there by inactivating the catalytic reaction either by competitive or noncompetitive mode of reactions. PIs have multiple functions by interfering with the proteolytic activity of the target proteases in the organisms. Diverse types of PIs have been isolated, characterized and evaluated for their biological potentials [3]. Mostly, PIs are produced in the organisms in response to various stresses such as pathogens, insects, wounding, and environmental parameters like salinity, heavy metals and temperature. The microbicidal mode of action of PI is either via inactivating the hydrolase enzymes or depolarization of plasma membrane of the invading organisms thereby inhibiting its growth and development. The insecticidal role of PIs is based on their inhibitory activities against the digestive enzymes of predators and pathogens resulting in to critical shortage of essential molecules or by interfering with important biochemical or physiological processes such as moulting or replication. Further, PIs play an important role in regulation of cell cycle, cell death, differentiation and immunity reactions [4].

Similarly, PIs have long been used as antinutritional, antimetastatic and anti-inflammatory molecules. The physiological functions of many plant PIs are largely inferred from their developmental and tissue specific expression patterns. The most extensively analyzed protease inhibitors in plants were serine and cysteine protease inhibitors. Miller et al., [5] reported some small in vivo PIs derived from the modification process of multidomain precursors. In addition, many plant PIs do not inhibit their own proteases but have specificities against animal or invading microbial enzymes. Solanum taxa showed this unique molecule with wide variations in terms of structure and function.

\section{Solanum group}

Solanum (Solanaceae), a group of annual or short lived perennial herbaceous weeds, distributed throughout the temperate and tropical regions of the world. Solanum contributes the largest and most complex genus with more than 2,000 species. Solanum species represent nearly $1 \%$ of the world's angiosperm flora, which might beat tribute to its great antiquity and an extraordinary rate of speciation. This huge diversity makes Solanum an interesting life form in terms of its evolutionary and economic stand point of view. Examples of food plants in Solanum were potato, eggplant, naranjilla, jasmine nightshade and others [6]. Many species of Solanum were used as medicine to cure digestive, intestinal problems like stomachache, diarrhoea, piles, dysentery and also for various skin problems such as sores, boils, cuts, wound, bruises, fever and malaria, headache and rheumatism. Some species were stimulants whereas others have sedative properties. Furthermore, many species were employed against respiratory tract disorders such as cough, sore throat, bronchitis, asthma and urinary problems. Most of the medicinal attributes of the species was due to the presence of steroidal glycoalkaloids [7]. Similarly, Solanum species shows insecticidal and fungicidal properties. $S$. nigrum, the black nightshade, a noxious weed but effectively inhibit the gut proteinases of pests and could potentially be used in generating insect resistant transgenic plants.

\section{Solanum protease inhibitors}

Generally, PIs are classified, based on the enzyme type they inhibit such as serine protease inhibitors and others [8]. The classification is also performed based on sequence homology like kunitz-type inhibitors. Further, they are also grouped in to different families based on their mass, architecture, number of disulphide bridges, 
isoelectric points and mechanism of action. Solanum species represents repository of protease inhibitor (PIs) diversity.

Serine Protease inhibitors (SPI) represent the largest family of inhibitors distributed throughout in plants. They are low-molecular mass proteins (3-25 $\mathrm{kDa}$ ) that inhibit trypsin and/or chymotrypsin. SPIs are classified into different classes on the basis of amino acid sequence and mechanism of interaction including $\alpha$-helical, $\beta$-sheet and $\mathrm{a} / \mathrm{b}$ proteins, as well as small disulfide rich proteins. Based on their mechanisms of action, three types of SPIs were recognized like canonical, non-canonical inhibitors and serpins. SPIs such as trypsin, elastase, chymotrypsin are the most intensively studied groups [9].

Potato serine protease inhibitor (PSPI) is a heterodimeric doubleheaded crystal kunitz-type SPI. PSPI show a $\beta$-coiled structure with two reactive site loops comprising Phe75 and Lys95 residues [10]. It is further sub-divided into Potato inhibitor type-I (PI-I) and type-II (PI-2) families. PI-II showed inhibition against trypsin, $\alpha$-chymotrypsin and elastase. The potato (Solanum tuberosum) tuber is a rich source of SPIs and carboxypeptidase inhibitors. Potato inhibitor I, is a small pentameric molecule of $8 \mathrm{kDa}$ protein. It is an inhibitor of chymotrypsin, subtilisin and trypsin. Further, potato also contains two other homologous SPIs such as PCI and PTI which are also homologous with inhibitor aubergine isolated from the exocarps of Solanum melongena and also from tomato and potato leaves [11].

SPIs from leaves were best analyzed from Solanaceous species, i.e., when leaves were wounded mechanically or through insects initiates the synthesis of diverse SPIs [12]. The newly synthesized inhibitors show a high degree of homology with potato I and potato II inhibitors already reported from potato tubers [13, 14].

Ryan and Balls [15] isolated potato inhibitor type-I from tubers of potato followed by Wingate et al., [16] from tomato fruits and leaves as a consequence of wounding [17]. It is a double headed molecule, each subunit possess an S-S bond capable of inhibiting tyrpsin and $\alpha$-chymotrypsin. Potato inhibitor II were reported from the leaves, flowers, fruit and phloem of Solanaceaous species [18] and was also purified from tomato [19]. Purified PIs from S. nigrum was also characterized and evaluated in terms of its medicinal potentialities [20]. Kunitz-type PIs, the most common type reported from cereals, legumes and in members of Solanaceae. Stress inducible trypsin inhibitor was found in potato tubers ( $S$. tuberosum) [21]. Metallocarboxypeptidase and aspartyl protease inhibitor have been identified in tomato and potato (table 1). Potato leaves also contain potato type I and type II inhibitors induced as a consequence of wound. The carboxypeptidae inhibitors isolated from potato were small sized inhibitors and are stabilized by many disulfide bridges [22]. Potato tuber protein consists a major storage protein patatin, and also some low kDa PIs which can be classified in to ten different groups. [23, 24]. The most common inhibitors belong to serine proteases of Kunitz-type inhibitors (KTI), potato protease inhibitors I and II (PIN I, PIN II) and Bowman-Birk inhibitors (BBIs). KTIs were also other best characterized inhibitors. These vacuolar proteins were abundant in potato tubers and represent a complex diverse group of proteins [25]. Metallo carboxyprotease inhibitor (MCPIS) includes metallocarboxy peptidase inhibitor and $\alpha$-cathepsin-D inhibitor family. They were small protein inhibitors isolated from potato and tomato consisting of 38-39 amino acids with $3 \mathrm{~S}-\mathrm{S}$ bonds with molecular mass of $42 \mathrm{kDa}$ [26]. MCPIS competitively inhibit a broad spectrum of carboxy peptidases from microbes and animals but not the serine carboxy petidases from yeast and plants [27]. These inhibitors also inhibit the activity of thermolysin, matrilysin, neutrophil, collagenase, interstitial collagenase, atrolysin C, stromelysin, carboxypeptidase $\mathrm{A}$, and TNF- $\alpha$ convertase. The potato carboxypeptidase inhibitor extracted from $S$. tuberosum inhibits thermolysin metallocarboxypeptidase.

Table 1: Diversity of PIs from Solanum species

\begin{tabular}{lll}
\hline Type & Source & Target protease \\
\hline $\begin{array}{l}\text { Proteinase inhibitor } \\
\text { II }\end{array}$ & Solanum tuberosum & Trypsin, Chymotrypsin \\
$\begin{array}{l}\text { Cathepsin D inhibitor } \\
\text { Kunitz cysteine peptidase } \\
\text { inhibitor } 1\end{array}$ & $\begin{array}{l}\text { Solanum tuberosum } \\
\text { Solanum tuberosum }\end{array}$ & Cathepsin D, Trypsin \\
$\begin{array}{l}\text { Chymotrypsin inhibitor } 1 \\
\text { Potato peptidase inhibitor }\end{array}$ & Solanum tuberosum & Cysteine proteases \\
II inhibitor unit 1 & Solanum tuberosum \\
$\begin{array}{l}\text { Tomato peptidase inhibitor } \\
\text { II inhibitor unit } 1\end{array}$ & Solanum lycopersicum & Trypsin, Chymotrypsin \\
Tomato peptidase inhibitor & & Trypsin, Chymotrypsin \\
II inhibitor unit 2 & Solanum lycopersicum & Trypsin, Chymotrypsin \\
\hline
\end{tabular}

Potato, inhibitor I was regulated by wounding and developmental process while, tobacco inhibitor I protein was related with senescence only. [35]. Potato protein, potamin-1 (PT-1) isolated from the watersoluble fraction of potato tuber (S. tuberosum L. cv. Gogu valley) shows protease inhibitory and antimicrobial activity [36]. This PT-1 was a 5.6 $\mathrm{kDa}$ trypsin-chymotrypsin protease inhibitor, with $62 \%$ homology to serine protease inhibitor. Potamin-1 had the ability to inhibit trypsin, chymotrypsin, and papain. These SPIs have diverse roles such as antiinflammatory, tissue repair and host defence [37]. Valueva et al., [38] studied the time course and the composition of proteinaseinhibiting proteins accumulation from the potato tubers diffusates and its elicitation using salicylic, jasmonic, and arachidonic acids. Jasmonic and arachidonic acids activated the accumulation of the chymotrypsin inhibitors in the tubers in response to the injury, whereas salicylic acid inhibited this process which suggest its role in the lipoxygenase metabolism of signal transduction of the anti-injury defense system in the dormant potato tubers.

Aspartic proteinase inhibitor corresponding to the group cathepsin D inhibitors (CDIs) was studied in S. tuberosum comprising 15 isoforms with significant sequence similarity [39]. The two isoforms of CDI were reported includes PDI (Protein disulfide isomerase) and NDI (naphthalene-diimide) which shows inhibitory activity against aspartate proteinases [40].
Kazal family are double headed inhibitors which inhibit trypsin and chymotrypsin simultaneously and were identified by Kazal et al. [41]. Kazal protein domain is an evolutionary conserved region of serine protease inhibitors. Six types are recognized. With ten consensus variable contact positions and the 19 possible variants at each of these positions were reported. Kazal 1 domains often occur in tandem arrays of small $\alpha+\beta$ fold containing three disulfide bonds capable of inhibiting trypsin and elastase inhibitor, avian ovomucoid, acrosin, elastase inhibitor via the amino terminal region of this domain binds to the active part of its target proteases, thus inhibiting their function. Kazal 2 domain is an indicative of SPI of Merops inhibitor groups comprising I1, I2, I17 and I31. This was also noticed in the extracellular part of agrins, which are not PIs. Kazal PIs reported from $S$. tuberosum and tomato shows fungicidal activity against Phytophthora infestans [42]. Trypsin inhibitors were the well characterized PIs forms stable complex with trypsin at 1:1 molar ratio for inhibiting the enzymatic action.

Aberoumand [43] evaluated qualitative phytochemical analysis of $S$. indicum and reported the presence of polyphenols, saponins, alkaloids, phytic acid, saponins and PIs. Inhibitory potential of trypsin inhibitor was $10.6 \mathrm{TIU} / \mathrm{g}$. Studies on $S$. stramonifolium also revealed the presence of peptides (or protein) in the seed aqueous extract that act as potential protease inhibitors [44]. 


\section{Purification and characterization of Solanum PI}

PIs have immense applications from plant protection to antiviral/anticancer. Hence, the discovery of novel PIs with new properties are of great interest. Park et al., [45] isolated and purified Kunitz-type serine protease inhibitor from potato ( $S$. tuberosum) using chromatographic techniques. Sritanyarat et al., [46] isolated and characterized isoinhibitors of the potato protease inhibitor I family from the latex of Hevea brasiliensis, that strongly inhibits subtilisin A. PIs from S. aculeatissimum was characterized and was a potential source of many biological properties such as analgesic, anti-inflammatory, anti-hypertensive and anti-microbial. Doubleheaded protease inhibitor was isolated, purified and characterized including its kinetics from the fruits of Solanum aculeatissimum (SAPI) [47]. Kunal et al., [48] isolated, purified and characterized a $20 \mathrm{kDa}$ protein, named PotHg, showing hemagglutination activity from tubers of Indian potato, S. tuberosum. The biochemical activity of many individual plant KTIs from potato has been analysed extensively and represents the largest KTI family [49]. Further, the KTI family showed unique sequence variation, including many nonsynonymous substitutions and loops, which appear to translate into functional diversity in the plants.

\section{Solanum PI genes}

PLANT-PIs is a document created to unravel the information on plant PIs and related genes. For each PI, links to sequence databases were reported together with an abstract of the functional features of the molecule. 351 plant PIs+several isoinhibitors were deposited in the data bank.

Five diverse Kunitz PI (KPI) group B genes were characterized by Speranskaya et al., [50] from the diploid genome of the non-potato species $S$. palustre. From cultivated potato accessions, 3 genes share a similarity index of $99 \%$ to KPI-B genes and 2 genes showed about $96 \%$ identity. KPI-B2 and KPI-B4 proteins from S. palustre contain conserved residues that involved to trypsin and chymotrypsinspecific binding sites of KPI-B, respectively. Analysis of inhibition of trypsin and chymotrypsin by Spls-KPI proteins, five of them were produced in $E$. coli purified using $\mathrm{Ni}$-sepharose resin and ionexchange chromatography. The recombinant Spls-KPI-B inhibited trypsin; K(i) values ranged from 84.8 (Spls-KPI-B4), 345.5 (Spls-KPIB1), and $1310.6 \mathrm{nM}$ (Spls-KPI-B2) to 3883.5 (Spls-KPI-B5) and 8370 nM (Spls-KPI-B3). Further, Spls-KPI-B1 and Spls-KPI-B4 inhibited chymotrypsin. Results suggest that regardless of substitutions of key active-center residues both Spls-KPI-B4 and Spls-KPI-B1 were functional trypsin-chymotrypsin inhibitors.

18 clones representing copies of 4 Kunitz-type PI group B genes (PKPI-B) obtained by PCR cloning of $S$. tuberosum L. cv. Istrinskii) genomic DNA were sequence analyzed by Speranskaya et al., [51]. 3 novel genes such as PKPI-B1, PKPI-B2, and PKPI-B10 represented by five, two, and seven clones, respectively. The remaining four clones were related to the PKPI-B9 gene. These data show that at least four PKPI-B encoding genes are harbored in the genome of the cultivar. Their analysis reveals that variability of PKPI-B encoding genes in potato was limited and could be explained by cross-hybridization events in the ancestor forms rather than by random mutagenesis.

$\mathrm{Xu}$ et al., [52] suggested that PIs offer insect resistance in transgenic plants but their endogenous functions remain undefined. Expression analysis of a PI II (PIN2) from S. americanum from phloem tissue of stems, roots and leaves suggesting its novel endogenous role. Two cDNAs encoding PIN2, SaPIN2a and SaPIN2b, from cDNA library were isolated using tomato PIN2 cDNA as hybridization probe. SaPIN2a shows $73.6 \%$ identity to SaPIN2b and further confirmed by Southern blot analysis. Northern blot analysis reveals that the two genes were wound inducible fifhowers. SaPIN2a was expressed more in stems. In situ hybridization analyzes on stem showed that SaPIN2a mRNA is expressed in companion cells and some sieve tubes. Western blot analysis using SaPIN2a-specific antibodies showed SaPIN2a accumulation in stems, leaf midribs and fruits. Immuno-histochemical localization, using these antibodies, revealed SaPIN2a expression in external and internal phloem of stem and further confirmed by immuno electron microscopy. The study suggests the role of SaPIN2a in proteolysis in the phloem.
Krinitsina et al., [53] studied group A Kunitz-type PIs (KPI-A) of potato involved in protecting them from pests and pathogens. KPI-A fragments were cloned, amplified, sequenced, and analyzed from the subgenera Potatoe sect. Petota (5 genes from S. tuberosum ssp. andigenum and 2 genes from $S$. stoloniferum) and Solanum (5 genes from $S$. nugrum), and their consensus sequences were established. $97-100 \%$ identity was seen among these sequences and the KPI-A sequences of Petota (cultivated potato Solanum tuberosum ssp. tuberosum) and Etuberosum (S. palustre). The interspecific diversity of $K P I-A$ did not exceed its intraspecific variation. The distribution of highly variable and conserved sequences in the mature proteincoding area was the same in all the species. In $S$. dulcamara, $S$. lycopersicum, and Mandragora officinarum the same primers are unable to amplify the homologous genes and the phylogenetic analysis grouped $S$. lycopersicum seperately from other species like $S$. nigrum. The cluster comprises of species of the sections $E$. tuberosum and Petota.

Although $S$. nigrum is resistant to the strains of the oomycete Phytophthora infestans, which causes dreadful diseases of Solanaceae, the amino acid sequences encoded by $S$. nigrum KPI-A differed slightly, if at all, from their counterparts of cultivated potato, which is susceptible to $P$. infestans infection.

Hartl et al., [54] analyzed four different Serine PI profile of S. nigrum. Transcript and activity characterization showed tissue-specific and insect-elicited accumulation patterns. Stable and transient gene silencing of SPIs displayed different specificities for target proteinases: the novel SPI2c revealed high specificity for trypsin and chymotrypsin, while two other SPI 2 homologs were highly active against subtilisin. Field and lab analyzes of SPIs to display herbivoreand gene-specific defensive properties, with dissimilar effects on closely related species. No visible developmental phenotype in SPIsilenced plants, suggesting that SPIs do not involve in regulating endogenous proteases.

Fischer et al., [55] studied diverse families from PIs of potato cultivars. The functional diversity was analyzed by sequencing 9,600 cDNA clones originated from 10 mature potato cultivar tubers. 120 unique inhibitor cDNA clones were screened by homology searches. 88 inhibitors represented novel sequence variants. Kunitz type inhibitors (KTI), potato protease inhibitors I and II (PIN), pectin methylesterase inhibitors, metallocarboxypeptidase inhibitors and defensins were common among them. 23 inhibitors were functionally characterized and among them eleven were pharmacological relevant proteases. The purified recombinant proteins were evaluated for their inhibitory activities on trypsin. Members of the KTI and PIN families inhibited pig pancreas elastase, $\beta$-Secretase, Cathepsin K, HIV-1 protease and potato 5-lipoxygenase.

Heibges et al., [49] revealed that kunitz-type enzyme inhibitors of potato were polymorphic small proteins. 55 variable DNA sequences from mature cultivars like Provita and Saturna analysed by expressed sequence tags showed high sequence similarity to KPIs.

The frequency of Kunitz-type inhibitor ESTs in Provita was 4 folds higher than in Saturna tubers, and none of the Provita ESTs was identical to any of the Saturna ESTs. The phenogram of the deduced amino acid sequences of the inhibitors resulted A, B and C homology groups. Group A derived from Provita ESTs and group B each other show more similarity than group C. Non-conservative amino acid substitutions and insertion/deletion polymorphisms reveal functional differentiation among members of the gene family. 21 genes for Kunitz-type enzyme inhibitors $(6,9,6$ for group A, B and $6 \mathrm{C}$ respectively) were estimated to exist in the potato genome. Genetic mapping and the identification of bacterial artificial chromosome clones showing more than one member of the gene family indicated that most inhibitor genes of groups A, B and C were grouped in a cluster that maps to a single region potato chromosome III.

Anna et al., [56] studied the effect of recombination on gene polymorphism encoding Kunitz-type PIs in Solanum. 12 different genes encoding KPIs from S. tuberosum and S. palustre were analyzed revealing their mosaic structural features. According to Zawala and Baldwin [57]. Trypsin PI gene expression in Nicotiana attenuata was up regulated during pest infection. Moulin et al., [58] 
examined the gene expression of PIs, specifically trypsin inhibitors, in the leaf extract of Capsicum baccatum var. pendulum inoculated with Pepper yellow mosaic virus. Revina et al., [59] isolated Subtilisin PI gene from potato tubers. The inhibitor has no effect on trypsin, chymotrypsin, and the cysteine proteinase papain. The $\mathrm{N}$ terminal sequence of the protein consists of 19 amino acid residues and was highly homologous to sequences of the group $C$ of the subfamily of potato Kunitz-type PIs (PKPIs-C). By cloning PCR products from the genomic DNA of potato, a gene denoted as PKPI$\mathrm{C} 2$ was isolated and sequenced. The $\mathrm{N}$-terminal sequence (residues from 15 to 33 ) of the protein encoded by the PKPI-C2 gene is identical to the N-terminal sequence (residues from 1 to 19) of the isolated protein PKSI. Thus, the inhibitor PKSI was seemed to be encoded by this gene. Pouvreau et al., [60] isolated and sequenced the gene of the most abundant PI in potato cv. Elkana which show $98 \%$ identity with potato serine PI (PSPI), of the Kunitz family. Antibodies were raised against the two most abundant isoforms of PSPI. The binding of these antibodies to PSPI isoforms and PIs from different groups of PI in potato showed $70 \%$ resemblance to the protease inhibitors present in potato juice.

\section{Transgenic plants with Solanum PI genes}

Proteinase inhibitor II (PIN2) with trypsin and chymotrypsin inhibitory activities belongs to SPI was first reported from tomato and potato [61]. Modern strategy in crop breeding to defend pest/pathogen is by insertion and expression of plant defence proteins. $\mathrm{Xu}$ et al., [62] isolated two cDNA clones encoding PIN2, designated SaPIN2 $a$ and SaPIN $2 b$ from screening cDNA library prepared from wounded leaves of wild American black nightshade ( $S$. americanum) using a tomato PIN2 cDNA as heterologous hybridization probe. The inhibitors from four families of serine PIs have been induced sequentially in various plants. These families include potato and tomato inhibitors I and II of solanaceous plants [63]. Silvia and Baldwin [64] compared wild type plants and transformed plants with an inverted repeat prosystemin construct (IRSys) to silence the expression of the endogenous $S$. nigrum prosystemin gene. Wild type species elicited with wounding+oral secretions from the larvae of Manduca sexta showed the synthesis of trypsin proteinase inhibitors (TPIs) even though prosystemin transcripts were down regulated. The constitutive expression of PIs, which has been reported to occur in storage organs and the reproductive tissues of plants, may fulfil anti-insecticidal as well as other endogenous functions in plants. Plants can differentially perceive various kinds of insect attacks and respond appropriately through activating plant defences including regulation of PIs at transcriptional and post-translational levels. Wound-inducible Pin-II proteinase inhibitors (PIs) were studied extensively for their structural and functional diversity and also their relevance in plant defence against insect pests.

Sin and chye [65] analyzed the expression of proteinase inhibitor II proteins during floral development in $S$. americanum. Further, both SaPIN2a and SaPIN2b were expressed in floral tissues that was destined to undergo developmental programmed cell death (PCD), suggesting its possible endogenous roles in inhibiting trypsin and chymotrypsin like activities during ontogeny of flowers.

The genetically modified (GM) crops expressing PIs are being tried as an alternative to GM crops with Bt toxins. It is advantageous to introduce PI genes in plants as they are naturally present in plants, so that the chances of adverse effects on human and other animals is eliminated. But many of the GM crops expressing protease inhibitors were not significant as the insects develop resistance by secreting proteases insensitive to inhibitors or by degrading PIs [66]. Available biochemical and molecular evidence indicates that many insects acclimatize to PIs by overproducing existing digestive proteases [67]. Characterization studies of potato PI II reactive site mutants by Beekwilder et al., [68] reported that Potato PI II (PI-2) is composed of two reactive site domains and assessed the role of its two reactive sites with the inhibition of trypsin and chymotrypsin by mutating each of the two reactive sites in multiple ways. Studies proved that the second reactive site strongly inhibits both trypsin and chymotrypsin. Meanwhile, the first reactive site inhibits only chymotrypsin. Lison et al., [69] reported a tomato wound-inducible protein called jasmonic-induced protein 21 (JIP21) which was a strong chymotrypsin inhibitor belonging to the Serine PIs group.

Potato PI-II gene of potato was introduced into many japonica rice cultivars to produce transgenic rice resistance against insect in vitro trials. Wound-inducible PI-II promoter with the first intron of rice actin I gene was capable to give significant expression of PI-II gene in transgenic rice. These transgenic plants were resistant to pink stem borer (Sesamia inferens) [70].

\section{Biological potentialities}

\section{Antimicrobial}

Fungal disease regulation can be executed in both nonpharmacological method ie, by maintaining personal hygiene and also by pharmacological method that can be executed by administering proper antifungal drugs based on the cause of the infecting fungi [71]. PIs are able to affect fungi by inhibiting extracellular and/or intracellular proteases that display important roles in metabolic and infection processes. Park et al., [45] purified AFP-J (antifungal protein) from tubers of $S$. tuberosum cv. L Jopung by using different chromatographic columns. Purified AFP-J strongly inhibited fungal strains like Candida albicans, Trichosporon beigelii, and Saccharomyces cerevisiae and which has $83 \%$ homology with SPI belonging to the Kunitz family. Trypsin-chymotrypsin inhibitor from $S$. tuberosum strongly inhibited the pathogenic fungi $C$. albicans and Rhizoctonia solani and showed $62 \%$ homology with PIs from Kunitz family and interestingly, no lysis of human erythrocytes suggesting the safety of PI as antimicrobial agent. Juleita et al., [72] reported antimicrobial effect of $S$. tuberosum aspartic proteases against Fusarium solani and Phytophthora infestans directly through interaction with the microbial cell surfaces followed by membrane permeabilization. Further, the inhibitors proved fungicidal against $F$. solani by targeting protease secreted by them.

Transgenic rice contain rice actin I gene+wound inducible PI-II promoter showed resistance against pink stem borer [73]. Potide-G, a small (5578.9 Da) antimicrobial peptide was isolated from tubers of $S$. tuberosum cv. Golden Valley was capable of suppressing the proteolytic activity of trypsin, chymotrypsin and papain effectively.

Kim et al., [74] demonstrated that inhibitors from potato tubers strongly inhibited the growth of a wide variety of bacteria like Staphylococcus aureus, Listeria monocytogenes, Clavibacter michiganense, and Escherichia coli, and fungi such as Candida albicans and Rhizoctonia solani. Different results reported by Bar-Ziv et al., [75] related with the synthesis and induction in tomatoes as a defence mechanism against many pathogens including Tomato yellow leaf curl virus (TYLCV). In the absence of pathogen exposure, the inhibitor level detected was minimal. Potide-G, a small (5578.9 $\mathrm{Da}$ ) antimicrobial peptide, was isolated from potato tubers (Solanum tuberosum L. cv. Golden Valley). Sanchez-Serrano [76] reported potato proteinase inhibitor-II (PI-II) and its constitutive expression in tubers and floral buds by wounding the leaves. Further, proteomic evidence of the wound-healing mechanisms of PIs from potato tissue was proved by Chaves et al., [77] using 2-D electrophoresis and further identified using MS/MS analysis.

\section{Insecticidal activity}

The insecticidal potential of PPIs was investigated as early as 1947, when Mickel and Standish observed the larvae of certain insects were unable to develop normally on soybean products. These inhibitors were proteins or peptides capable of inhibiting catalytic activities of proteases. They are grouped in to serine, cysteine, aspartic or metallo protease inhibitors. Diverse protease have been identified from the extracts of the digestive tracts of insects from many families, particularly those of Lepidoptera and many of these enzymes are inhibited by PIs. Broadway and Duffey [78] compared the effects of purified soybean birk trypsin inhibitor (SBTI) and potato inhibitor II (an inhibitor of trypsin and chymotrypsin) on the growth and digestive physiology of larvae of Heliothis zea and Spodoptera exigua and proved that growth of larvae was inhibited at various levels. Potato tubers possess an aspartic proteinase inhibitor, cathepsin D that shares considerable amino acid sequence identity with the trypsin inhibitor-SBTI from soybeans [79]. 
Dunse et al., [80] studied molecular basis for the resistance of Helicoverpa larvae chymotrypsin to a potato type II proteinase inhibitor from Nicotiana alata. Effect of PIs of S. lycopersicum against Leptinotarsa decemlineata on defences was evaluated by Seung and Gary [81]. The fourth-instar larvae were reared on the leaves of $S$. lycopersicum resulted in to the induction of transcripts of the proteinase inhibitors pin1 and pin2. Mosolov [63] reported that the Chymotrypsin PIs from $S$. tuberosum suppress the growth and development of the oomycete of $P$. infestans. Urwin et al., [82] reported that transgenic $S$. tuberosum express proteinase inhibitors against Globodera pallida and there by offering resistance.

Hartl et al., [83] identified four SPI from $S$. nigrum differ substantially in substrate specificity, accumulation patterns, and their insecticidal mechanisms. Hartl et al., [54] reported high variations in constitutive levels of trypsin inhibitors expression among control and S. nigrum exposed to Spodoptera exigua. Intrinsic inhibitors from this plant may affect larval pest growth, indicating a potential natural defence mechanism against herbivore insects.

Remya et al., [84] screened plant extracts containing protease inhibitors against gut proteases of Spodoptera mauritia larvae. 20\% inhibition of gut protease activity of Spodoptera mauritia larvae were obtained by S. melongena and S. lycopersicum
Transgenic petunia, birch and lettuce of Potato PI-I and PI-II genes displayed resistance against insect pests. Transgenic tobacco with chymotrypsin inhibitor gene of potato enhances resistance agaisnt Chryodeixis eriosoma [73]. The protease inhibitor gene CpTi was successfully transferred producing transgenic tobacco with significant resistance against tobacco hornworm (Manducta sexta) [85]. Sane et al., [86] studied the efficiency of transgenic tobacco plants expressing CpTi was tested against armyworm in feeding trails under laboratory conditions. Reduction to the extent of $50 \%$ was observed in the biomass of army worm larvae fed on transgenic leaves expressing 3-5 $\mu \mathrm{g}$ of $\mathrm{CpTi} / \mathrm{g}$ of fresh leaves. Tomato plants over expressing JIP21 have been generated and showed resistance against larvae of the Lepidopteran Egyptain cotton worm [87].

Enzyme threonine deaminase (TD), of $S$. lycopersicum serves dual role in isoleucine (Ile) biosynthesis in plants and Thr degradation in the insect midguts of Manduca sexta, where they destroy these nutritionally important amino acids, ultimately resulting in decreased larval growth [88]. Egyptian cotton worm larvae fed on transgenic tomato plants overexpressing JIP21 (strong chymotrypsin inhibitor belonging to the Ser proteinase inhibitors) showed an increase in mortality and delay in growth when compared with larvae fed on wildtype plants. These larvae belong to the Lepidoptera group with digestive enzymes belongs to Ser proteases [39] (table 2).

Table 2: Solanum protease inhibitors active against insect pests

\begin{tabular}{llll}
\hline Inhibitor type & Crop & Pest & Reference \\
\hline Tomato inhibitor I and II & Tobacco & M. sexta & Johnson et al., [89] \\
Nicotiana alta protease inhibitor (PI) & Tobacco & Helicoverpa punctigera & Heath et al., [90] \\
Potato inhibitor II & & Heliothis zea & Broadway and Duffey [79] \\
& & Spodoptera exigua & \\
Nicotiana alta protease inhibitor (PI) & Peas & Plutella xylostella & Charity et al., [91] \\
\hline
\end{tabular}

PP (potato protein) may be an alternative to medicated feed with antibiotics because it showed antimicrobial activity against coliform bacteria and also improve the performance of weanling pigs [92].

\section{Antiherbivore defenses}

Trypsin Protease Inhibitors (TPIs) expression studies revealed the evidence for plant defence function of TPIs. In Nicotiana attenuate, manipulation of its endogenous trypsin PIs production demonstrates their antiherbivore effects. [93]

Ali et al., [94] revealed a novel mechanism for the epigenetic basis of HIPV-mediated habituation by evaluating the recalled expression of Bowman-Birk trypsin inhibitor gene. Moreover, in the promoter region of trypsin inhibitor gene, the methylation sites were found to be demethylated by the HIPV treatments.

\section{Antioxidant (AOX)}

Plant biomolecules display significant levels of antioxidants that can play a potential role in RBC membrane protection and reduce oxidative damages in the cells [95]. S. aculeatissimum PI exhibited significant IC 50 values for most of the AOX assays i.e., DPPH radical scavenging, reducing power, metal chelating ability, ABTS and $\mathrm{OH}$. radical scavenging activity were comparable with the synthetic antioxidants like ascorbate and BHT. Free radicals scavenging activity of PI may be through the H-atom abstraction from the free hydroxyl group [96]. Mayasa et al., [97] evaluated antioxidant potential of $S$. tuberosum protease inhibitors. The partially purified PI using ammonium sulfate precipitation was analysed in terms of proteolysis assay using casein as substrate and antioxidant activity by DPPH and $\mathrm{H}_{2} \mathrm{O}_{2}$ scavenging.

\section{Antiviral}

Molecular investigations on viral proteases reveals their prominent role in cleavage of viral polyprotein precursors and also in catalyzing the processing of the structural proteins necessary for the assembly and morphogenesis of virus particles [98]. Studies on in vitro antiviral activity of $S$. nigrum by Javed et al., [99] suggest that $S$. nigrum extract in combination with interferon is a potential drug to cure Hepatitis C Virus infection.

\section{Phylogenetic analysis}

Faiza et al., [100] carried out an in vitro and in silico characterization of $S$. lycopersicum wound-inducible proteinase inhibitor-II gene. In silico insight of the phylogenetic evaluation revealed that 30 PIs from diverse plants share a common mother stock of evolutionary origin. Molecular and phylogenetic analysis of the wound-inducible PI-I gene was attempted for the 7 direct ancestors of tomato such as Lycopersicon esculentum: L. pennellii, L. chilense, L. hirsutum, $L$. parviflorum, $L$. peruvianum var. humifusum, $L$. cheesmanii, and $L$. Peruvianum [101].

Due to the zebra chip disease, caused by Candidatus liberibacter solanacearum (CLso), a decreased protease inhibitor content was observed in matured potato that results in an enhanced serine protease activity and altered protein profiles. Patatin, serine, aspartine and cystatin type protease inhibitors were either absent or greatly reduced in ZC affected tubers [102].

Weeda et al., [103] analysed correlative changes in proteases and protease inhibitors during mobilisation of protein in potato seed tubers. They reported that catabolism of protease inhibitors may facilitate protein mobilisation from seed tubers.

\section{CONCLUSION}

The diverse PI genes from Solanum species and their combination products are targeted at different pharmaceutical and agricultural levels. These include protease inhibitor genes and also lectins, $\alpha$ amylase inhibitors, or other plant genes encoding insecticidal or anticancer potentiality. These researches minimize the use of synthetic drugs in near future by effectively complementing plant derived products. Recombinant PIs may also be an alternative way to protect plants from pathogens. Currently, screening gene pools without taxonomic constraint can help identify novel lead molecule for multipurpose needs. Exploring insecticidal proteins involved in host plant defense can lead to effective control of pest. This strategy 
is an output of co-expression of numerous factors, each of which could be custom engineered by directed molecular evolution to maximize its effectiveness against implementing integrated pest management programs.

\section{ACKNOWLEDGEMENT}

The authors are grateful for Department of Science and Technology, Govt. of India for providing INSPIRE fellowship for the programme. (Fellowship order no. IF130468).

\section{CONFLICTS OF INTERESTS}

\section{Declared none}

\section{REFERENCES}

1. Birk Y. Plant protease inhibitors, significance in nutrition, plant protection, cancer prevention and genetic engineering, springer-verlag berlin Heidelberg. $1^{\text {st }}$ edn; 2003. p. 1-5.

2. Laskowski M, Kato I. Protein inhibitors of proteinases. Annu Rev Biochem 1980;49:593-626.

3. Hung CH, Huang CC, Tsai WS, Wang HL, Chen YL. Purification and characterization of a trypsin inhibitor from Brassica campestris seeds. J Yuanpei Univ Sci Technol 2003;10:13-22.

4. Fan XM, Wong BCY, Wang WP, Zhou XM, Cho CH. Inhibition of proteasome function is induced apoptosis in gastric cancer. Int J Cancer 2001;93:481-8.

5. Miller EA, Lee MCS, Atkinson AHO, Anderson MA. Identification of a novel four-domain member of the proteinase inhibitor II family from the stigmas of Nicotiana alata. Plant Mol Biol 2000;42:329-33.

6. Edmonds JM. Biosystematics of Solanum L. section Solanum (Maurella). The Biology and Taxonomy of the Solanaceae. JG Hawkes, RN Lester, AD Skelding. eds. Academic Press: London; 1979a. p. 529-48.

7. Patel K, Singh RB, Patel DK. Medicinal significance, pharmacological activities, and analytical aspects of solasodine: a concise report of current scientific literature. J Acute Disease 2013;2:92-8.

8. Bode W, Hubr R. Natural protein proteinase inhibitors and their interaction with proteinases. Eur J Biochem 1992;204:433-51.

9. Barrett AJ, Rawlings ND, Woessner JF. Handbook of proteolytic enzymes. New York: Academic Press; 1998. p. 101-24.

10. Meulenbroek EM, Thomassen EA, Pouvreau L, Abrahams JP, Gruppen H, Pannu NS. The structure of a post-translationally processed heterodimeric double-headed Kunitz-type serine protease inhibitor from potato. Acta Crystallogr Sect D: Biol Crystallogr 2012;68:794-9.

11. Richardson M. Seed storage proteins: The Enzyme Inhibitors. In: LJ Rogers. ed. Methods in plant biochemistry amino acids, proteins, and nucleic acids New York: Academic Press; 1995;5:259-305.

12. Green TR, Ryan CA. Wound-induced proteinase inhibitor in plant leaves a possible defense mechanism against insects. Science 1972;175:776-7.

13. Kuo T, Pearce G, Ryan CA. Isolation and characterization of proteinase inhibitor I from etiolated tobacco leaves. Arch Biochem Biophys 1984;230:504-10.

14. Graham JS, Pearce J, Merryweather K, Titani LH, Ericsson, Ryan CA. Wound-induced proteinase inhibitors from tomato leaves. I. The cDNA-deduced primary structure of pre-inhibitor I and its posttranslational processing. J Biol Chem 1985a;260:6555-60.

15. Ryan CA, Balls AK. An inhibitor of chymotrypsin from Solanum tuberosm and its behavior toward trypsin. Proc Natl Acad Sci 1962;48:1839-44.

16. Wingate VP, Broadway RM, Ryan CA. Isolation and characterization of a novel, developmentally regulated proteinase inhibitor I protein and cDNA from the fruit of a wild species of tomato. J Biol Chem 1989;264:17734-8.

17. Lee JS, Brown WE, Graham JS, Pearce G, Fox EA, Dreher TW, et al. Molecular characterization and phylogenetic studies of a wound-inducible proteinase inhibitor I gene in Lycopersicon species). Proc Natl Acad Sci USA 1986;83:7277-81.

18. Pearce G, Johnson S, Ryan CA. Purification and characterization from Tobacco (Nicotiana tabacum) leave of six small, woundinducible, proteinase isoinhibitors of the potato inhibitor II family. Plant Physiol 1993;102:639-44.
19. Taylor BH, Young, Scheuring CF. Induction of a proteinase inhibitor II-class gene by auxin in tomato roots. Plant Mol Biol 1993;23:1005-14.

20. Schmidt DD, Kessler A, Kessler D, Schmidt S, Lim M, Gase K, et al. Solanum nigrum: a model ecological expression system and its tools. Mol Ecol 2004;13:981-95.

21. Ledoigt G, Griffaut B, Debiton E, Vian C, Mustel A, Evray G, et al. Analysis of secreted protease inhibitors after water stress in potato tubers. Int J Biol Macromols 2006;38:268-71.

22. Ryan CA. Proteolytic enzymes and their inhibitors in plants. Annu Rev Plant Physiol 1973;24:173-96.

23. De Leo F, Volpicella M, Licciulli F, Liuni S, Gallerani R, Ceci LR. PLANT-PIs: a database for plant protease inhibitors and their genes. Nucl Acids Res 2002;30:347-8.

24. Rawlings ND, Barrett AJ. Evolutionary families of peptidases. Biochem J 1993;290:205-18.

25. Heibges A, Salamini F, Gebhardt C. Functional comparison of homologous membranes of three groups of Kunitz-type enzyme inhibitors from potato tubers (Solanum tuberosum L). Mol Genet Genomics 2003;269:535-41.

26. Hass GM, Hermodson MA. Amino acid sequence of a carboxypeptidase inhibitor from tomato fruit. Biochemistry 1981;20:2256-60.

27. Havkioja E, Neuvonen L. Induced long-term resistance to birch foliage against defoliators: defense or incidental. Ecology 1985;66:1303-8.

28. Greenblatt HM, Ryan CA, James MNG. The structure of the complex of Streptomyces griseus proteinase B and polypeptide chymotrypsin inhibitor-I from russet Burbank potato tubers at 2.1 Å resolution. J Mol Biol 1989;205:201-28.

29. Strukelj B, Pungercar J, Mesko P, Barlic-Maganja D. Characterization of aspartic proteinase inhibitors from potato at the gene, cDNA and protein levels. Biol Chem Hoppe-Seyler 1992;373:477-82.

30. Gruden K, Strukelj B, Ravnikar M, Poljsak-Prijatelj M. Potato cysteine proteinase inhibitor gene family: molecular cloning, characterisation and immunocytochemical localization studies. Plant Mol Biol 1997;34:317-23.

31. Richardson M. Chymotryptic inhibitor I from potatoes. The amino acid sequence of subunit A. Biochem J 1974;137:101-12.

32. Keil M, Sanchez-Serrano J, Schell J, Willmitzer L. Primary structure of a proteinase inhibitor II gene from potato (Solanum tuberosum). Nucleic Acids Res 1986;14:5641-50.

33. Graham RA, Holland-Czytko H, Andersen JL, Ryan CA. Vacuolar localization of wound-induced carboxypeptidase inhibitor in potato leaves. Plant Physiol 1985;78:76-9.

34. Barrette-Ng IH, Ng KKS, Cherney MM, Pearce G. Structural basis of inhibition revealed by a 1:2 complex of the two-headed tomato inhibitor-II and subtilisin carlsberg. J Biol Chem 2003;278:24062-71.

35. Koiwa H, Bressan RA, Hasegawa PM. Regulation of protease inhibitors and plant defense. Trends Plant Sci 1997;2:379-84.

36. Kim JY, Chung YS, Paek KH, Park YI, Kim JK, Yu SN, et al. Isolation and characterization of a cDNA encoding the cysteine proteinase inhibitor, induced upon flower maturation incarnation using suppression subtractive hybridization. Mol Cells 1999;9:392-7.

37. Habib H, Fazili KM. Plant protease inhibitors: a defense strategy in plants. Biotechnol Mol Biol Rev 2007;2:68-85.

38. Valueva TA, Revina TA, Gvozdeva EL, Gerasimova NG, Ilhinskaia LI, Ozretskovakaia OL. Effects of elicitors on the accumulation of proteinase inhibitors in injured potato tubers. Appl Biochem Microbiol 2001;37:512-6.

39. Lison P, Rodrigo I, Conejero V. A novel function for the cathepsin D inhibitor in tomato. Plant Physiol 2006;142:1329-39.

40. Keilova $\mathrm{H}$, Tomasek V. Isolation and properties of cathepsin D inhibitor from potatoes. Collect Czech Chem Commun 1976;41:489-97.

41. Mistry R, Snashall PD, Totty N, Briskin S, Guz A, Tetley TD. Purification and characterization of a novel-type serine proteinase inhibitor of neutrophil elastase from sheep lung. Biochim Biophys Acta 1997;1342:51-61.

42. Miaoying Tian, Brett Benedetti, Sophien Kamoun. A second kazal-like protease inhibitor from Phytophthora infestans 
inhibits and interacts with the apoplastic pathogenesis-related protease P69B of tomato. Plant Physiol 2005;138:1785-93.

43. Ali Aberoumand. Screening of phytochemical compounds and toxic proteinaceous protease inhibitor in some lesser-known food based plants and their effects and potential applications in food. Int J Food Sci Nutr Eng 2012;2:16-20.

44. Sarnthima, Rakrudee, Khammuang, Saranyu. Antibacterial activities of Solanum stramonifolium seed extract. Int J Agric Biol 2012;14:111.

45. Park Y, Choi BH, Kwak JS, Kang CW, Lim HT, Cheong HS, et al. Kunitz-type serine protease inhibitor from potato (Solanum tuberosum L. cv. Jopung). J Agric Food Chem 2005;53:6491-6.

46. Sritanyarat W, Pearce G, Siems WF, Ryan CA, Wititsuwannakul $\mathrm{R}$, Wititsuwannakul D. Isolation and characterization of isoinhibitors of the potato protease inhibitor I family from the latex of the rubber trees, Hevea brasiliensis. Phytochemistry 2006;67:1644-50.

47. Meenu Krishnan VG, Murugan K. Purification, characterization and kinetics of protease inhibitor from fruits of Solanum aculeatissimum Jacq. Food Sci Human Wellness 2015;4:97-107.

48. Kunal R Shah, Dhaval K Patel, Anju Pappachan, C Ratna Prabha, Desh Deepak Singh. Characterization of a kunitz-type serine protease inhibitor from Solanum tuberosum having lectin activity. Int J Biol Macromol 2016;83:259-69.

49. Heibges A, Glaczinski H, Ballvora A, Salamini F, Gebhardt C. Structural diversity and organiza tion of three gene families for Kunitztype enzyme inhibitors from potato tubers (Solanum tuberosum L.). Mol Genet Genomics 2003;269:526-34.

50. Speransky AS, Cimaglia F, Krinitsina AA, Poltronieri P, Fasano $\mathrm{P}$, Bogacheva AM, et al. Kunitztype protease inhibitors group B from Solanum palustre. Biotechnol J 2007;2:1417-24.

51. Speransky AS, Cimaglia F, Krinitsina AA, Poltronieri P, Fasano P. Shevelev, et al. Molecular cloning of Kunitz-type proteinase inhibitor group B genes from potato, Biochemistry 2005;70:292-9.

52. Xu ZF, Qi WQ, Ouyang XZ, Yeung E, Chye ML. A proteinase inhibitor II of Solanum americanum is expressed in the phloem. Plant Mol Biol 2001;47:727-38.

53. Krinitsinaa B, Melnikovac MS, Belenikinc P, Poltronierid A, Santinod AV, Kudryavtsevac, et al. Polymorphism of the KPIA gene sequence in the potato subgenera Potatoe (Sect. Petota, Esolonifera, and Lycopersicum) and Solanum A. A. Mol Biol 2013;47:358-63.

54. Hartl M, Ashok P, Giri, Harleen Kaur, Ian Baldwin. Serine protease inhibitors specifically defend Solanum nigrum against generalist herbivores but do not influence plant growth and development. Plant Cell 2010;22:4158-75.

55. Fischer Matthias, Markus Kuckenberg, Robin Kastilan, Jost Muth, Christiane Gebhardt. Novel in vitro inhibitory functions of potato tuber proteinaceous inhibitors. Mol Gen Genom 2015;290:387-98.

56. Anna Speranskaya, Anastasia Krinitsina A, Kudryavtseva AV, Palmiro Poltronieri, Angelo Santino. The impact of recombination on polymorphism of genes encoding Kunitztype protease inhibitors in the genus Solanum. Biochimie 2012;94:1687-96.

57. Zavala JA, Baldwin IT. Fitness benefits of trypsin protease inhibitor expression in Nicotiana attenuata are greater than their costs when plants are attacked. BMC Ecol 2004;4:11.

58. Moulin MM, Rodrigues R, Ribeiro SFF, Gonçalves LSA, Bento CS, Sudré CP, et al. Trypsin inhibitors from Capsicum baccatum var. pendulum leaves involved in pepper yellow mosaic virus resistance. Genet Mol Res 2014;13:9229-43.

59. Revina TA, Speranskaya AS, Kladnitskaya GV, Shevelev AB, Valueva TA. Subtilisin protein inhibitor from potato tubers. Biochemistry (Moscow) 2004;69:1092-8.

60. Pouvreau L, Gruppen H, Piersma SR, van den Broek LAM, van Koningsveld GA, Voragen AGJ. Relative abundance and inhibitory distribution of protease inhibitors in potato juice from cv Elkana. J Agric Food Chem 2001;49:2864-74.

61. Liu J, Xia KF, Deng YG, Huang XL, Hu BL, Xu X, et al. The nightshade proteinase inhibitor Ilb gene is constitutively expressed in glandular trichomes. Plant Cell Physiol 2006;47:1274-84.
62. Xu ZF, Teng WL, Chye ML. Inhibition of endogenous trypsin and chymotrypsin-like activities in transgenic lettuce expressing heterogeneous proteinase inhibitor SaPIN2a. Planta 2004;218:623-29.

63. Mosolov VV, Valueva TA. Proteinase inhibitors and their function in plants: a review. Appl Biochem Microbiol 2005;41:227-46.

64. Silvia S, Ian TB. Systemin in Solanum nigrum. The tomatohomologous polypeptide does not mediate direct defense responses. Plant Physiol 2006;142:1751-8.

65. Sin SF, Chye ML. Expression of proteinase inhibitor II proteins during floral development in Solanum americanum. Planta 2004;219:1010-22.

66. Cloutier C, Jean C, Fournier M, Yelle S, Michaud D. Adult colorado potato beetles, Leptinotarsa decemlineata compensate for nutritional stress on Oryza cystatin I-transgenic potato plants by hypertrophic behavior and over-production of insensitive proteases. Arch Insect Biochem Physiol 2000;44:69-81.

67. Pallavi Sharma, Ambuj Bhushan Jha, Rama Shanker Dubey, Mohammad Pessarakli. Reactive oxygen species, oxidative damage, and antioxidative defense mechanism in plants under stressful conditions. J Bot 2012;26. http://dx.doi.org/ 10.1155/2012/217037

68. Beekwilder J, Schipper B, Bakker P, Bosch D, Jongsma M. Characterization of potato proteinase inhibitor II reactive site mutants. Eur J Biochem 2000;267:1975-84.

69. Lison P, Rodrigo I, Conejero V. A novel function for the cathepsin D inhibitor in tomato. Plant Physiol 2006;142:1329-39.

70. Duan X, Li X, Xue Q, Abo-El-Saad M, Xu D, Wu R. Transgenic rice plants harboring an introduced potato proteinase inhibitor II gene are insect resistant. Nat Biotechnol 1996;14:494-8.

71. Ari Y, Kusnandar A, Riana Annisa NA. Antifungal activity of kombucha tea against human pathogenic fungi, Asian J Pharm Clin Res 2016;9:253-5.

72. Julieta RM, Mariana RP, Fernando FM, Gustavo RD, Maria GG. Antimicrobial activity of potato aspartic proteases (StAPs) involves membrane permeabilization. Microbiology 2006;152:2039-47.

73. Ussuf KK, Laxmi NH, Mitra R. Proteinase inhibitors. Plantderived genes of insecticidal protein for developing insectresistant transgenic plants. Curr Sci 2001;7:847-53.

74. Kim MH, Park SC, Kim JY, Lee SY, Lim HT, Cheong H, et al Purification and characterization of a heat-stable serine protease inhibitor from the tubers of new potato variety "Golden Valley". Biochem Biophys Res Commun 2006;346:681-6.

75. Bar-Ziv A, Levy Y, Hak H, Mett A. The tomato yellow leaf curl virus (TYLCV) V2 protein interacts with the host papain-like cysteine protease CYP1. Plant Signaling Behav 2012;7:983-9.

76. Sanchez-Serrano JJ. Abscisic acid and jasmonic acid activate wound-inducible genes in potato through separate, organspecific signal transduction pathways. Plant J 1997;11:773-82.

77. Chaves MM, Flexas J, Pinheiro C. Photosynthesis under drought and salt stress: regulation mechanisms from whole plant to cell. Ann Bot 2009;103:551-60.

78. Broadway RM, Duffey SS. Plant proteinase inhibitors: mechanism of action and effect on the growth and digestive physiology of larval Heliothis zea and Spodoptera exigua. J Insect Physiol 1986b;32:827-33.

79. Paulraj KL, Kripa RK. Plant protease inhibitors in control of phytophagous insects. Elect J Biotechnol 2002;5:93-109.

80. Dunsea KM, Kaasc Q, Guarinoa RF, Bartond D, Craikc J, Anderson MA. Molecular basis for the resistance of an insect chymotrypsin to a potato type II proteinase inhibitor. Proc Natl Acad Sci USA 2010;107:15016-21.

81. Seung Ho Chung, Gary W Felton. Specificity of induced resistance in tomato against specialist lepidopteran and coleopteran species. J Chem Ecol 2004;37:378-86.

82. Urwin PE, Troth KM, Zubko EI Atkinson HJ. Effective transgenic resistance to Globodera pallida in potato field trials. Mol Breed 2001;8:95-101.

83. Markus Hartl, Ashok PG, Baldwin IA. The multiple functions of plant serine protease inhibitors. Plant Signaling Behav 2011;6:1009-11. 
84. Remya PP, Sameena U, Bindu PP, Kannan KM. Identification of plant extracts containing protease inhibitors against the gut proteases of Spodoptera mauritia Boisduval (Lepidoptera: Noctuidae). Acta Biol Indica 2013;2:451-5.

85. Hilder VA, Gatehouse AMR, Sheerman SE, Barker RF, Boulter D. A novel mechanism of insect resistance engineered into tobacco. Nature 1987;300:160-3.

86. Sane VA, Nath P, Aminuddin, Sane PV. Development of insectresistant transgenic plants used in plant genes: expression of cowpea trypsin inhibitor in transgenic tobacco plants. Curr Sci 1997;72:741-7.

87. Novatus F Mushi, Zakaria H Mbwambo, Ester Innocent, Supinya Tewtrakul. Antibacterial, anti-HIV-1 protease and cytotoxic activities of aqueous ethanolic extracts from Combretum adenogonium Steud. Ex A. Rich (Combretaceae). BMC Complementary Altern Med 2012;12:163.

88. Chen H, Wilkerson CG, Kuchar JA, Phinney BS, Howe GA. Jasmonate-inducible plant enzymes degrade essential amino acids in the herbivore midgut. Proc Natl Acad Sci USA 2005; 102:19237-42.

89. Johnson R, Narraez J, Ryan CA. Expression of proteinase inhibitors I and II in transgenic tobacco plants: effects on natural defense against Manduca sexta larvae. Proc Natl Acad Sci USA 1989;86:9871-75.

90. Heath RG, Mc Donald JT, Christeller M, Lee K, Bateman J, West $\mathrm{R}$, et al. Proteinase inhibitors from Nicotiana alata enhance plant resistance to insect pests. J Insect Physiol 1997; 9:833-42.

91. Charity Julia AA, Merilyn AB, Dennis JW, Malcom Higgins TJV. Transgenic tobacco and peas expressing a proteinase inhibitor from Nicotiana alata have increased insect resistance. Mol Breed 1999; 5:357-65.

92. Plate NA, Valuev TA, Valueva VV. Biospecific haemo sorbents based on proteinase inhibitor. I. Synthesis and properties. Biomaterials 1993;14:51-6.

93. Jorge AZ, Aparna GP, Klaus Gase, Dequan Hui, Ian TB. Manipulation of Endogenous trypsin proteinase inhibitor production in Nicotiana attenuata demonstrates their function as antiherbivore defenses. Plant Physiol 2004;134:1181-90.
94. Ali M, Koichi Sugimoto, Abdelaziz Ramadan, Gen-ichiro Arimura. The memory of plant communications for priming anti-herbivore responses. Sci Reports 2013;3:18-25.

95. Nwaoguikpe RN, Braide W, Ezejiofor TI. The effect of Aloevera plant (aloe barbadensis) extracts on sickle cell blood (HbSS). Afr J Food Sci Technol 2010;1:58-63.

96. Meenu Krishnan VG, Murugan K. Antioxidant power of purified protease inhibitors from the fruits of Solanum aculeatissimum Jacq. J Pharm 2016;6:231-40.

97. Vinyas Mayasa, Vijay Kumar R, Banappa SU. Evaluation of phenol content, antioxidant, and proteinase inhibitory activity of plant derived protease inhibitors of eight anti-diabetic plants. Asian J Pharm Clin Res 2016;9:215-9.

98. Patick AK, Potts KE. Protease inhibitors as antiviral agents. Clin Microbiol Rev 1998;11:614-27.

99. Tariq Javed, Usman Ali Ashfaq, Sana Riaz, Sidra Rehman, Sheikh Riazuddin.'In vitro antiviral activity of Solanum nigrum against Hepatitis C Virus. Virol J 2011;8:26-34.

100. Faiza M, Syed Muhammad Saqlan, Tariq M. In vitro and in silico characterization of Solanum lycopersicum wound-inducible proteinase inhibitor-II gene. Turkish J Biol 2013;37:1-10.

101. Lee JS, Brown WE, Graham JS, Pearce G, Fox EA, Dreher TW, et al. Molecular characterization and phylogenetic studies of a wound-inducible proteinase inhibitor I gene in Lycopersicon species). Proc Natl Acad Sci USA 1986;83:7277-81.

102. Kumar GN, Lisa OK, Richard K. Zebra chip disease decreases tuber (Solanum tuberosum L.) protein content by attenuating protease inhibitor levels and increasing protease activities. Planta 2015;242:1153-66.

103. Weeda SM, Kumar GNM, Knowles NR. Protein mobilization from potato tubers during long-term storage and daughter tuber formation. Int J Plant Sci 2011;172:459-70.

\section{How to cite this article}

- Meenu Krishnan VG, Murugan K. Solanum protease inhibitors and their therapeutic potentialities: a review. Int J Pharm Pharm Sci 2016;8(12):14-21. 